\title{
Detecting iron-based pigments on ruthenium-coated ancestral Pueblo pottery using variable pressure scanning electron microscopy
}

\author{
M. W. Pendleton ${ }^{1 *}$, D. K. Washburn², E. A. Ellis ${ }^{3}$ and B. B. Pendleton ${ }^{4}$
}

\begin{abstract}
Background: Ancestral Puebloan black-on-white ceramics of the American Southwest can be classified as containing pigments within their painted designs containing high levels of organic-based elements such as potassium, or mineral-based elements such as iron, or a mixture of these elements. The identification of pigment elements of the pottery of a site is fundamental in determining the site's cultural and temporal context. This paper will concentrate only on the analysis of mineral based pigment which was shown by previous researchers to exhibit greater concentrations of iron than organic based pigment. Although the visual discrimination of these pigments can be difficult if the pigment is a mixture of both pigment types or if the pigment is worn, this paper will describe a sherd sample previously shown to contain only mineral pigment. For the present study, a Tescan variable pressure scanning electron microscope, a JEOL 6400 scanning electron microscope, and a Hitachi S-3400 N scanning electron microscope were used with the same sherd. This sherd was coated with ruthenium to reduce charging without the visual color change associated with sputtered metal coatings. A reduction in microscope chamber vacuum also greatly reduced charging of unpainted areas. An energy dispersive spectrometry detector produced a map of the iron present in the sherd. Areas of iron in the sherd were identified using a backscatter electron detector. Iron as well as other elements present in the paint pigment was also detected using micro-X-ray fluorescence on the same sherd.
\end{abstract}

Results: The images and maps produced by the Tescan variable pressure scanning electron microscope did not always show well-defined iron-based pigmented areas on the sherd. Although the secondary image taken with a high vacuum did not show clear boundaries of the pigment on the sherd, a secondary image taken at a low vacuum of the same area showed well defined pigment boundaries. Other images taken with this microscope such as the backscatter image showed boundaries of sections of the pigment and the energy dispersive spectroscopic map showed a green colored pattern corresponding in general to the pigment area of the sherd containing iron. Using micro-X-ray fluorescence, the Hitachi S-3400 N scanning electron microscope mapped the following elements: iron, aluminum, potassium, calcium, sulfur, and silicon at a high vacuum with excellent resolution primarily for iron in the paint pigment on the sherd.

Conclusions: The best resolved image of iron-based pigment for the ruthenium coated sherd was obtained using the low vacuum secondary detector in the Tescan Vega 3 XMU. Excellent resolution for the energy dispersive spectrometry maps for iron was obtained by the micro-X-ray fluorescence detector on the Hitachi S-3400 N scanning electron microscope.

\footnotetext{
*Correspondence: mikep@tamu.edu

${ }^{1}$ Microscopy and Imaging Center, Interdisciplinary Life Sciences Building,

Texas A\&M University, Mail Stop 2257, College Station, TX 77843-2257,

USA

Full list of author information is available at the end of the article
} 
Keywords: Iron, Pigment, Archeological pottery, Scanning electron microscopy

\section{Background}

The classification of the type of pigments applied to the pottery sherds or vessels recovered at an archeological site is vital to the determination of the cultural and temporal context of the site. The traditional Pueblo pigment types are carbon-based (containing organic compounds, primarily potassium [1], mineral-based (containing primarily iron [2] compounds), or in some cases a mixture of these types. Throughout the Pueblo sequence from the advent of pottery making (c. AD 600 to the contact period, AD 1600), these pigment types appear to correspond to regional cultural groups and temporal changes in these groups. For example, in southern Utah and southwestern Colorado, carbon-based paints characterize the type sequences of western Pueblo black-on-white pottery types in Arizona and in the Mesa Verde/Colorado River/San Juan River area. In contrast, in northwestern and southwestern New Mexico, mineral painted wares dominate the Chaco and Mimbres sequences. These pigment types are typically distinguished in the field and in most lab analyses by visual inspection. The carbonbased pigments are usually characterized by their fuzzy edge and their apparent penetration into the clay matrix while mineral-based pigments appear to have worn or flaked off the clay surface [3]. Researchers [2] have validated the accuracy of these observer-based identifications using scanning electron microscopy (SEM) coupled with energy dispersive spectroscopy (SEM-EDS) to identify the elements present in pottery pigments. They determined that the accuracy of visual identifications was $84.2 \%$ for fifteen Mesa Verde White Ware sherds from Wallace Ruin in southwestern Colorado.

However, carbon (typically potassium-based) and mineral (typically iron-based) pigment types can be difficult to distinguish if they are combined or "mixed" or if much of the paint is worn [2]. Visual identification is inadequate for these cases. For example, a researcher [3] on the ceramics from the La Plata district, a southern extension of the Mesa Verde carbon painted area, has advocated that thermal and chemical tests should be used to validate visual evaluations of paint pigments. Another researcher [4] also advised that chemical tests be used for sherds from Montezuma Canyon, southeastern Utah. A more precise determination of either mineral or carbon-based pigment than merely visual observation was stipulated by [5] to classify the pottery of the eastern San Juan Basin and the Acoma-Laguna regions of the American Southwest.

In order to distinguish mineral pigments from organic pigments in painted Ancestral Puebloan pottery, [2] used scanning electron microscopy (SEM) coupled with energy dispersive spectroscopy (SEM-EDS). To prepare the sherds for SEM, they applied a coating of carbon on the surface of their sherds to control SEM charging effects. These effects can reduce the clarity of the image, cause a smearing of the image, and produce bright areas with corresponding loss of detail. While the carbon coating allowed precise mapping of the boundaries of the iron (in the mineral based pigment) in backscatter SEM mode, the dark black carbon coating visually obscured the paint pigment boundaries. To avoid the use of carbon coating to reduce charging, this paper describes alternative methods to control charging such as (1) the addition carbon and copper tape (Fig. 1) to the outer edges of the sherd, (2) the use of ruthenium vapor coating [6] to reduce charging without the visual color change associated with sputtered metal coatings and (3) the use of a lowered SEM vacuum pressure in secondary imaging mode. To demonstrate the effect of ruthenium coating

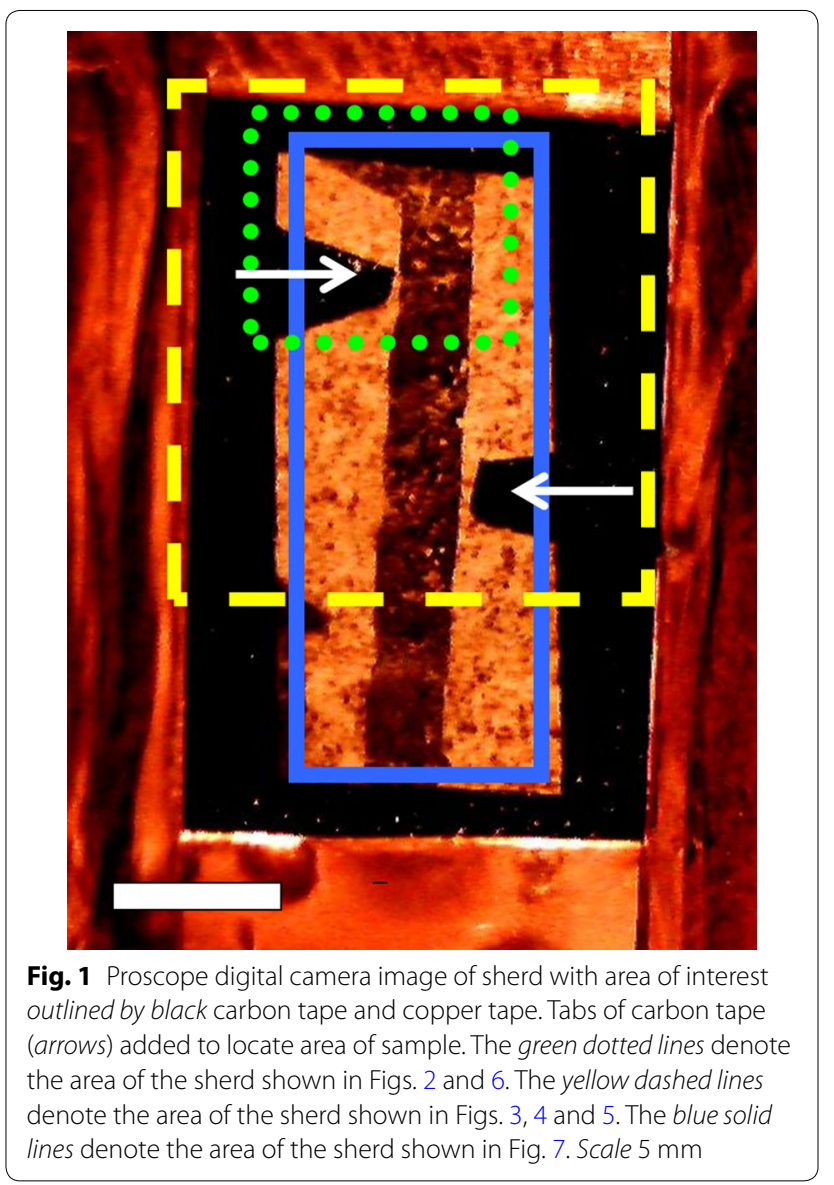


as an aid to reduce charging, a secondary electron image (Fig. 2) of the sherd before coating was applied taken (using $30 \mathrm{keV}$ ) utilizing a JEOL 6400 SEM at a chamber vacuum of $5.0 \mathrm{e}-3 \mathrm{~Pa}$. Another secondary electron image of the same sherd (Fig. 3) following ruthenium coating was obtained $(30 \mathrm{keV})$ at a similar vacuum $(2.1 \mathrm{e}-2 \mathrm{~Pa})$ with the Tescan Vega SEM. For the uncoated sherd,

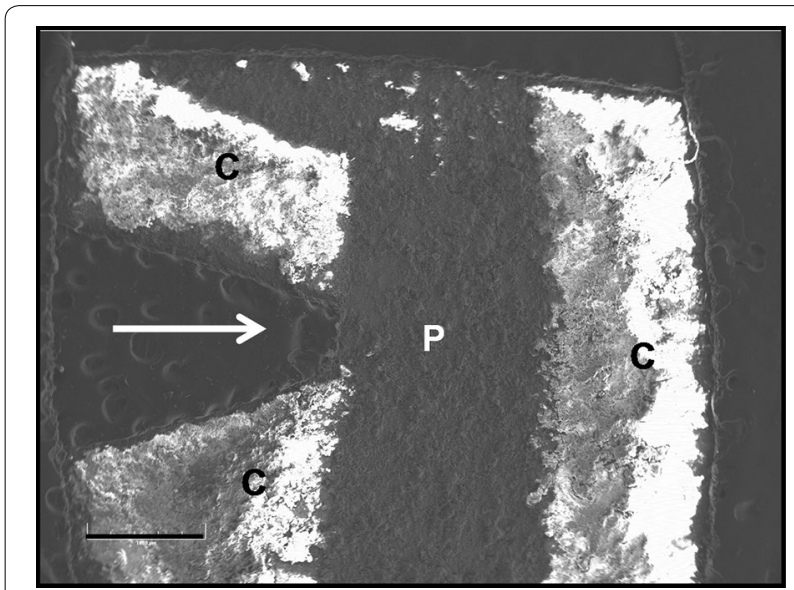

Fig. 2 JEOL 6400 SEM image of un-coated (no ruthenium) sherd at $30 \mathrm{keV}$ and a chamber vacuum of $5.0 \mathrm{e}-3 \mathrm{~Pa}$. A JEOL Everhart-Thornley secondary detector is used for this image. White arrow carbon tape, $C$ area of charging, $P$ area of paint pigment. Scale $1 \mathrm{~mm}$ charging was present in the unpainted areas of the sherd (Fig. 2) but the same sherd (following ruthenium coating) had far less charging present in the unpainted areas of the sherd (Fig. 3). The painted areas were grounded by the iron present in the pigment which provided a path to ground. At a reduced vacuum $(60 \mathrm{~Pa})$, but the same beam energy $(30 \mathrm{keV})$, the charging effects were greatly reduced on the unpainted areas of the same sherd surface so that the darker painted areas could be easily identified (Fig. 4). In this image, the caliche deposit on the sherd surface was easily resolved with the Tescan Vega 3 XMU SEM using the low vacuum Tescan secondary detector (LVTSD) with a built-in turbo molecular pump. An Oxford Energy Dispersive Spectrometry detector produced a map of the location of iron as an overlay in green (Fig. 5) using a vacuum of $2.3 \mathrm{e}-2 \mathrm{~Pa}$ over a secondary image $(30 \mathrm{keV})$ of the same sherd by the Tescan Vega 3 XMU SEM secondary detector. Another image of the same sherd (Fig. 6) was obtained (using $30 \mathrm{keV}$ at $2.2 \mathrm{e}-2 \mathrm{~Pa}$ vacuum) on the Tescan Vega $3 \mathrm{XMU}$ using the conductive annular mono-crystal scintillator-type (retractable) backscatter electron detector which demonstrated compositional contrast which allowed the identification of iron present in the brighter portions of the painted pigment area. Using a Hitachi S-3400 N SEM (at $5.0 \mathrm{e}-3 \mathrm{~Pa}$ vacuum), micro-X-ray fluorescence was used to map (Fig. 7) several elements including iron in the same sherd.

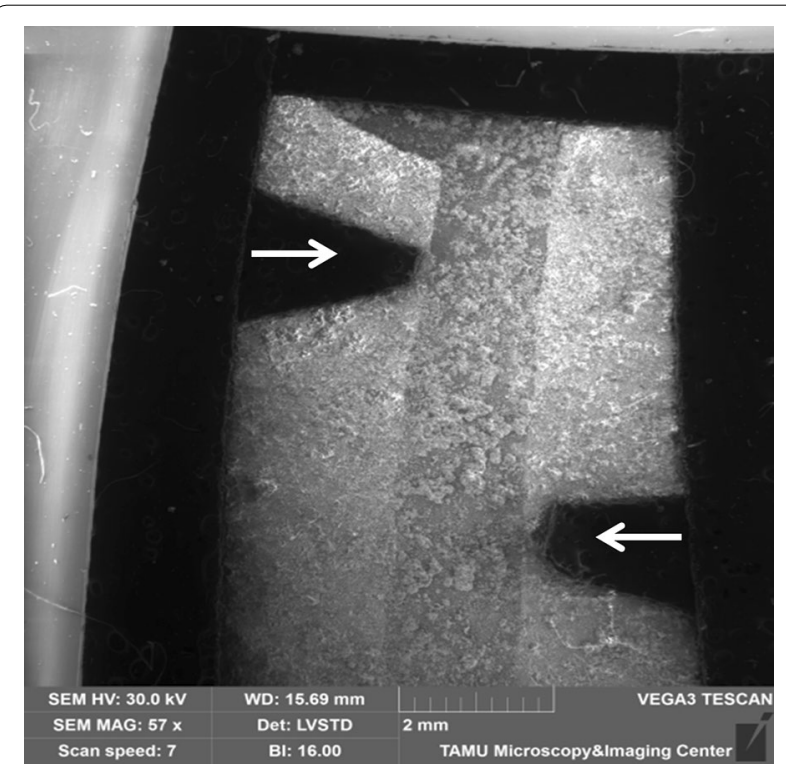

Fig. 4 Tescan Vege 3 XMU SEM secondary image of ruthenium coated sherd at 60 Pa vacuum. Tabs of carbon tape (arrows) added to locate area of sample. Low vacuum secondary Tescan detector (LVSTD) is used which has a turbo-molecular vacuum pump inside the detector. Almost all charging effect is eliminated. Scale $2 \mathrm{~mm}$ 


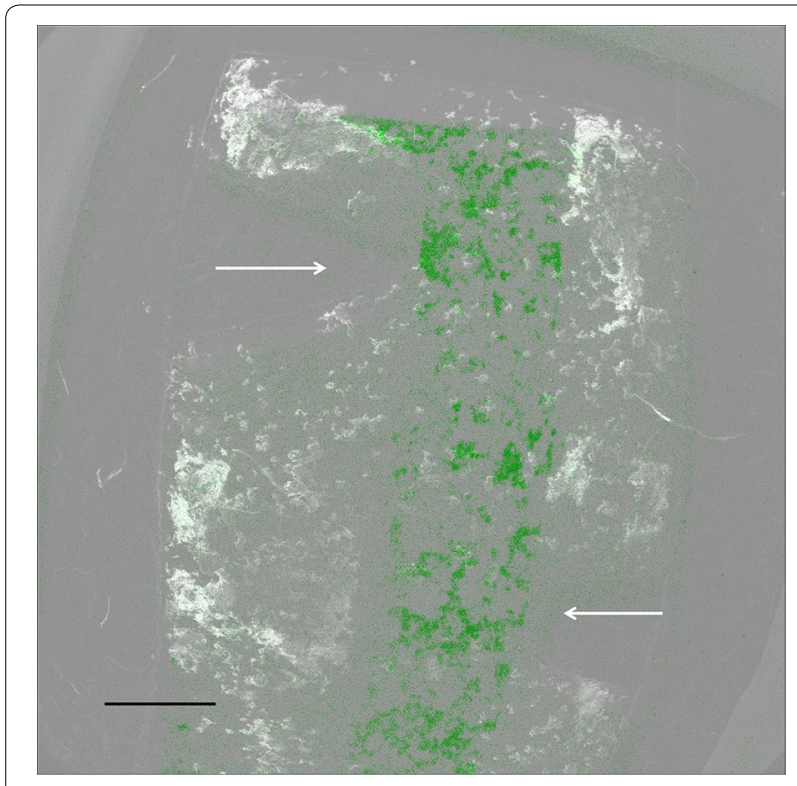

Fig. 5 Tescan Vega 3 XMU SEM secondary image (30 kV) of ruthenium coated sherd at $2.3 \mathrm{e}-2 \mathrm{~Pa}$ vacuum with an overlay using an Oxford Energy Dispersive Spectrometry detector to demonstrate the location of iron as a green color with Aztec software. Tabs of carbon tape (arrows) added to locate area of sample. Scale $2 \mathrm{~mm}$

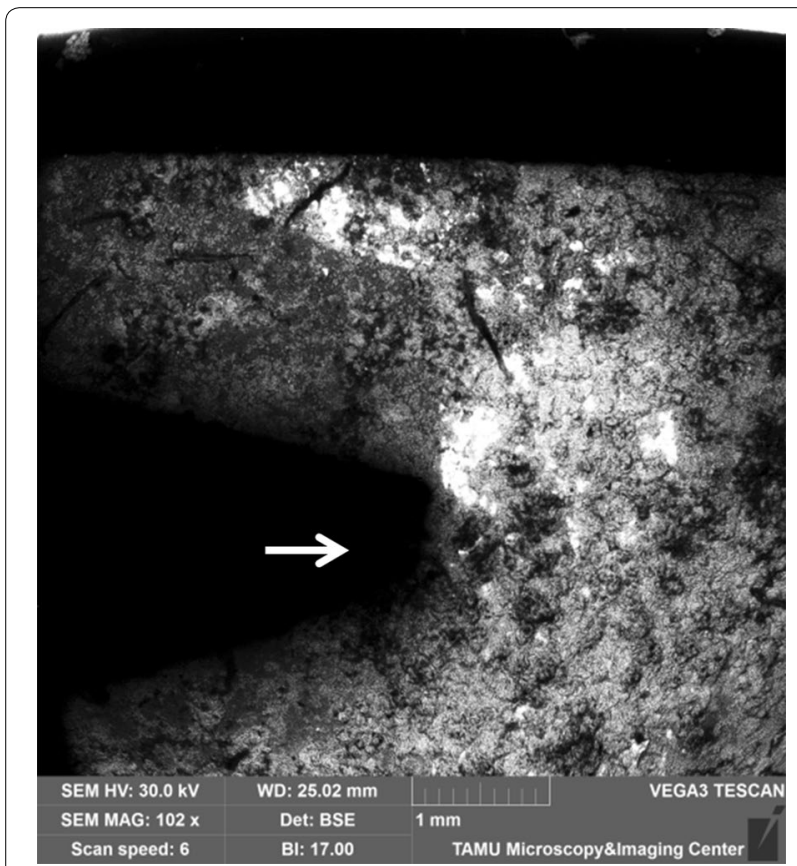

Fig. 6 Tescan Vega 3 XMU SEM backscatter image of ruthenium coated sherd at 2.3e-2 Pa vacuum. Tab of carbon tape (arrow) added to locate area of sample. Bright areas of compositional contrast are due to iron in paint pigment which is correlated to painted pattern shown in Fig. 1. Scale $1 \mathrm{~mm}$

\section{Results and discussion}

The SEM images used in this paper demonstrate different techniques used to reduce or eliminate the effects of charging without applying a carbon coating on the pottery sample which visually obscures the painted pottery designs. The image shown in Fig. 4 demonstrate that high resolution details of iron-based pigment with little or no charging can be best produced using the low pressure secondary detector at $60 \mathrm{~Pa}$ vacuum. The other images (Figs. 2, 3, 4, 5 and 6) were compared using the same primary beam energy as used in Fig. $4(30 \mathrm{keV})$ but with a different vacuum setting, a different detector, or an absence of coating for the same Ancestral Pueblo blackon-white pottery sherd.

SEM secondary image production begins with a primary beam of negatively charged electrons that penetrate the surface of the sample to induce the production of secondary electrons which are attracted to the positively charged grid in front of the secondary detector. These secondary electrons are used by the secondary detector to produce an image. However, if too many negatively charged electrons do not penetrate the sample surface and cannot find a pathway to a positive ground (along the ruthenium coating to the conducting carbon and copper tape attached to ground), then charging can occur with the accumulation of electrons on the sample. These accumulated electrons can be attracted to the secondary detector by the positively charged grid mounted over the scintillator producing bright areas on the image (charging) which do not reflect the topography of the sample surface.

The backscatter detector is typically mounted around the objective lens of the SEM and is divided into four quadrants. No positively charged grid is needed for attracting the electrons for this detector. The backscattered electrons were originally part of the incident beam but some may have lost energy. The backscatter detector will only detect electrons which have interacted elastically or quasi-elastically. Depending on how the signals from the four quadrants of the detector are combined, areas of the sample's atomic number, surface topography, and surface crystallography can be analyzed.

The Ancestral Pueblo pottery sherd is shown in Fig. 1 with carbon and copper tape surrounding the periphery to reduce charging. The pigment is visible as a black vertical band and triangular sections of black conductive tape (white arrows) were added to the unpainted area to facilitate locating the pigment areas in different imaging modes. The green dotted lines denote the area of the sherd shown in Figs. 2, 6. The yellow dashed lines denote the area of the sherd shown in Figs. 3, 4. The blue 


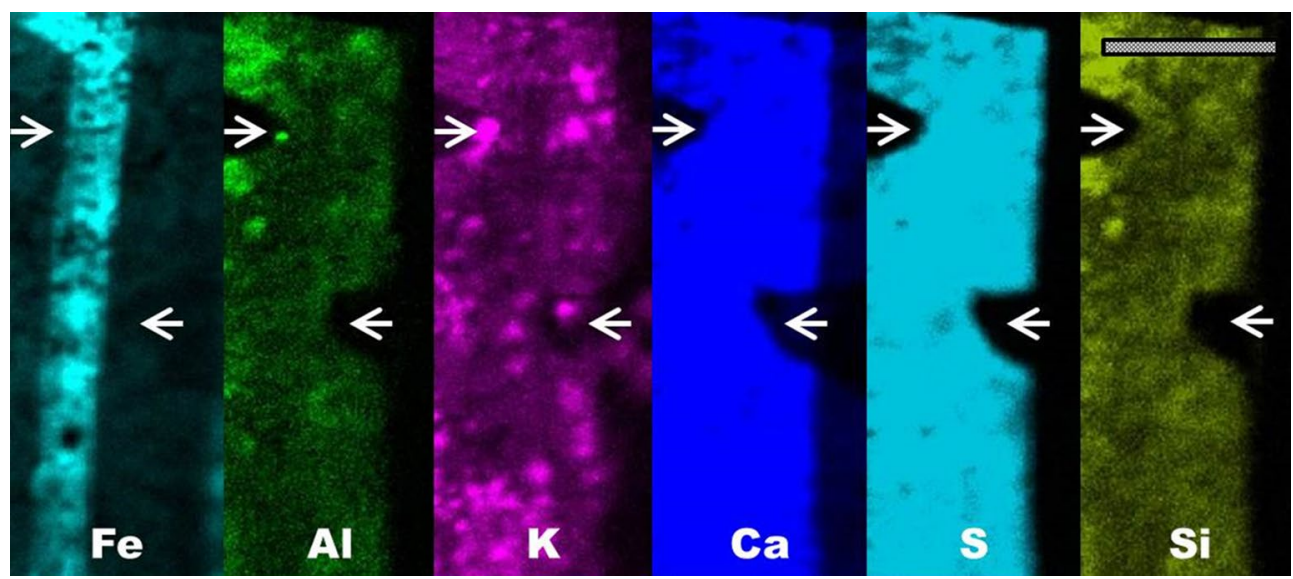

Fig. 7 Micro-XRF-SEM map showing areas of the sherd containing iron, aluminum, potassium, calcium, sulfur, and silicon. Tabs of carbon tape (arrows) added to locate areas of sample. A Hitachi S-3400 N SEM equipped with an X-ray source (IXRF Systems 10 um X-beam Micro-XRF using an $\mathrm{X}$-ray source monocapillary optic Rh tube operating at $50 \mathrm{kV}$ and $1000 \mu \mathrm{A}$ ) and an IXRF Systems (30 mm) EDS detector was used to produce the Micro-XRF-SEM elemental maps Scale $5 \mathrm{~mm}$

solid lines denote the area of the sherd shown in Fig. 7. Figures 2, 3, 4, 5 and 6 are all images of the rutheniumcoated sherd obtained with the Vega 3 SEM at $30 \mathrm{kV}$. Figure 2 image (produced with a JEOL 6400 SEM at $30 \mathrm{keV}$ and a chamber vacuum of $5.0 \mathrm{e}-3 \mathrm{~Pa}$ ) was not ruthenium-coated in order to demonstrate the increase in charging produced with no ruthenium coating present. The painted area was grounded by the iron pigment so that only the unpainted area of the sherd demonstrated the bright areas of charging. Another secondary electron image of the ruthenium coated sherd (Fig. 3) was obtained at a similar vacuum $(2.1 \mathrm{e}-2 \mathrm{~Pa})$ with the Tescan Vega $3 \mathrm{XMU}$ to demonstrate the reduction of charging due to the ruthenium coating. The image taken with a vacuum of $2.1 \mathrm{e}-2 \mathrm{~Pa}$ in secondary mode (Fig. 3) using an Everhart-Thornley detector did not show clear pigment boundaries on the sherd. However, the image of the same sherd taken at a lower vacuum of $60 \mathrm{~Pa}$ (Fig. 4) showed very well resolved pigment boundaries using the other Everhart-Thornley secondary Tescan detector (with a turbo-molecular vacuum pump inside the detector).

An Oxford Energy Dispersive Spectrometry detector (using Aztec software) produced a map of the location of iron as an overlay in green (Fig. 5) using a vacuum of $2.3 \mathrm{e}-2 \mathrm{~Pa}$ over another image of the sherd made by the Tescan Everhart-Thornley secondary detector at 2.1e-2 Pa with the Tescan Vega 3 XMU SEM. Figure 6 demonstrates the compositional contrast (brighter areas of iron) obtained with the Tescan Vega 3 XMU SEM at a vacuum of $2.3 \mathrm{e}-2 \mathrm{~Pa}$.

While the SEM-EDS detector (Oxford Inca X-act) on the Tescan Vega 3 produced an elemental map of iron (Fig. 6), the Micro-XRF-SEM detector on the Hitachi $\mathrm{S}-3400 \mathrm{~N}$ was able to produce elemental maps of iron and of aluminum, potassium, calcium, sulfur, and silicon (Fig. 7). The greater number of elements detected by Micro-XRF-SEM is due to the better signal to background ratio of XRF compared to SEM-EDS. The Minimum Detection Limits (MDL) of an electron beam are about $1000 \mathrm{ppm}$ (or 0.1 weight percent) but the MDL of an XRF beam is less than $100 \mathrm{ppm}$ [7].

\section{Experimental}

An Ancestral Pueblo pottery sherd from the American Southwest (Fig. 1) was used for this study. The dark black painted designs on the sherd matched the visual criteria used [2] to define mineral (or iron-based) paint pigment. The pottery piece was vapor coated with a thin coating of ruthenium as described in [6] to help reduce charging effects (blurred images from the SEM). Along with the ruthenium coating, carbon and copper tape were applied to the outside edges of the sherd (except for the section to be observed) and grounded to the specimen holder to further reduce the effects of SEM charging. The image of the sherd prepared for SEM in Fig. 1 was taken with a Proscope camera mounted to a dissection light microscope.

A Tescan VEGA 3 XMU variable pressure scanning electron microscope (VP-SEM) was used for this study equipped with two Everhart-Thornley type secondary detectors: a low vacuum secondary Tescan detector (LVSTD) and another Everhart-Thornley secondary detector for use with vacuum settings near $2.3 \mathrm{e}-2 \mathrm{~Pa}$. The LVSTD produces a secondary image by using a turbo molecular pump to keep the detector components vacuum (as low as $1000 \mathrm{~Pa}$ ) while an electron porous barrier isolates the detector from the higher vacuum $(2.3 \mathrm{e}-2 \mathrm{~Pa})$ SEM chamber. The low vacuum mode of the Tescan Vega 
3 serves to reduce the tendency of the sherd sample to charge in the SEM chamber (Fig. 4). A conductive annular mono-crystal scintillator-type (retractable) backscatter detector is also used in the Tescan Vega 3 VP-SEM to analyze the pigment present on the sherd (Fig. 6). An Oxford X-act energy dispersive spectrometer (EDS) (using Aztec software) is used on the Tescan Vega 3 to produce SEM-EDS (high vacuum mode) the elemental map of the location of iron in green on the sherd overlain by a secondary electron image (Fig. 5).

A Hitachi S-3400 N SEM equipped with an X-ray source (IXRF Systems $10 \mu \mathrm{m}$ X-beam Micro-XRF using an X-ray source monocapillary optic Rh tube operating at $50 \mathrm{kV}$ and $1000 \mu \mathrm{A})$ and an IXRF Systems $(30 \mathrm{~mm})$ EDS detector was used to produce the Micro-XRF-SEM elemental maps (Fig. 7) of the same Ancestral Pueblo pottery sherd analyzed with the Tescan Vega 3 . The same ruthenium coating along with conductive carbon and copper tape were utilized during Micro-XRF-EDS analysis in order to provide similar experimental sample conditions for a comparison with SEM-EDS.

\section{Conclusions}

The SEM images used in this paper demonstrate different techniques used to reduce or eliminate the effects of charging without applying a carbon coating on the pottery sample which visually obscures the painted pottery designs. For this study, ruthenium vapor coating was applied to the sherd to reduce charging because the coating did not visually obscure the painted designs of the sherd. Figure 2 shows a greater degree of charging prior to vapor coating while Fig. 3 shows the sherd with vapor coating exhibiting a lesser degree of charging than Fig. 2. The image shown in Fig. 4 demonstrate that high resolution details of iron-based pigment with little or no charging can be best produced (with ruthenium vapor coating) using the low pressure secondary detector at $60 \mathrm{~Pa}$ vacuum. The images (Figs 2, 3, 4, 5, 6) were produced using the same primary beam energy $(30 \mathrm{keV})$ but with a different vacuum setting, a different detector, or an absence of coating for the same Ancestral Pueblo black-on-white pottery sherd. Micro-XRF-SEM is more effective than SEM-EDS in locating trace elements (aluminum, potassium, calcium, sulfur, and silicon in addition to iron) (Fig. 7) in the paint and matrix of Ancestral Pueblo blackon-white pottery for the sherd sample tested. A previous study [8] examined a piece of the sherd used in the present study and in another previous study [9], the same sherd sample was used in the present paper to analyze archeological pottery pigments. Both of these previous studies employed a JEOL JSM 6400 high vacuum SEM without variable pressure capability. The Tescan Vega 3 LVSTD detector used in the present study better revealed the pigment boundaries of the pottery paint due to the lower SEM chamber vacuum and vapor coating which reduced charging effects (Fig. 4). The same Micro-XRFEDS data presented in [9] was included in the present paper for comparison with the SEM-EDS data obtained by VP-SEM. A more detailed explanation of the different detector designs and function of the SEM can be found in introductory sources such as [10].

\section{Methods}

In order to prepare samples for vapor coating, the sherd was attached to an SEM mounting stub with carbon tape and copper tape applied to the edges of the sample (Fig. 1) and placed in the vapor chamber. This ruthenium vapor protocol must be conducted in a properly functioning fume hood with a minimum flow rate of $100 \mathrm{ft} /$ min. Although osmium vapor coating has been used in some cases, only ruthenium vapors should be used for this type of SEM-EDS study since the osmium X-ray signal can interfere with the iron X-ray signal in the spectra. A plastic bottle cap was used to hold the vapor solution of $1 \mathrm{ml}$ of $10 \%$ (wt/vol.) sodium hypochlorite to $0.02 \mathrm{~g}$ ruthenium chloride $\left(\mathrm{RuCl}_{3} \cdot 3 \mathrm{H}_{2} \mathrm{O}\right)$. Ruthenium chloride and $10 \%$ sodium hypochlorite were purchased from Sigma Chemical Co., St. Louis, MO. Once these chemicals are combined, the reaction is rapid. A beaker of hot water on the vapor chamber expedites the vapor coating of the sample [6]. After the reaction, the sample (attached to the stub) can be placed in the SEM for observation and analysis. Unlike the appearance of a sherd following carbon coating, the ruthenium-coated sherd does not appear darker after the application of vapor coating.

\section{Abbreviations}

SEM: scanning electron microscope; EDS: energy dispersive spectrometer; SEM-EDS: energy dispersive spectrometry produced by electron beam in SEM; VP-SEM: variable pressure-scanning electron microscope; Micro-XRF-SEM micro-X-ray fluorescence produced by X-rays detected by EDS in SEM; LVSTD: low vacuum secondary Tescan detector; MDL: minimum detection limits; XRF: $X$-ray fluorescence.

\section{Authors' contributions}

MWP completed technical operation of VP-SEM and EDS, DKW provided the archeological context, EAE assisted in determination of optimal sample preparation, and BBP contributed to project conception and presentation of scientific data. All authors read and approved the final manuscript.

\section{Author details}

${ }^{1}$ Microscopy and Imaging Center, Interdisciplinary Life Sciences Building, Texas A\&M University, Mail Stop 2257, College Station, TX 77843-2257, USA.

${ }^{2}$ American Section, University Museum, University of Pennsylvania, Philadelphia, PA 19104, USA. ${ }^{3}$ Microscopy Consulting Technologist, P.O. Box 6124, Thomasville, GA 31758, USA. ${ }^{4}$ Department of Agricultural Sciences, West Texas A\&M University, Box 60998, Canyon, Texas, TX 79016-0001, USA.

\section{Acknowledgements}

The authors acknowledge Kenny Witherspoon and Mandi Hellested of IXRF Systems for the Micro-XRF-SEM analysis of the sherd and for sharing their scientific expertise. 


\section{Competing interests}

The authors declare they have no competing interests.

Received: 26 June 2015 Accepted: 19 April 2016

Published online: 19 May 2016

\section{References}

1. Pendleton MW, Washburn DK, Ellis EA, Pendleton BB. Distinguishing between mineral paint and carbon paint on ancestral Puebloan pottery. Micros Today. 2012;20:32-6.

2. Stewart JD, Adams KR. Evaluating visual criteria for identifying carbonand iron-based pottery paints from the Four Corners region using SEMEDS. Amer Antiq. 1999;64:675-96.

3. Shepard AO. Ceramics for the archaeologist. Washington: Carnegie Institution of Washington; 1956.
4. Nelson FW. A simple method for distinguishing between organic and inorganic paints on black-on-white Anasazi pottery. Amer Antiq. 1975:40:348-9

5. Roney JR. The prehistoric Pueblo world A.D. 1150-1350. Tucson: University of Arizona Press; 1996.

6. Ellis EA, Pendleton MW. Vapor coating: a simple, economical procedure for preparing difficult specimens for scanning electron microscopy. Micros Today. 2007;15:44.

7. Witherspoon KC, Cross BJ, Hellested MD. Combined electron and X-ray excitation for spectrometry in the SEM. Micros Today. 2013;21:24-8.

8. Pendleton MW, Ellis EA, Washburn DK, Pendleton BB. An analysis of prehistoric pottery paint composition utilizing energy dispersive spectroscopy. Micros Microanal. 2009;15:1518-9.

9. Pendleton MW, Washburn DK, Ellis EA, Pendleton BB. Detecting ironbased pigments on ruthenium-coated archaeological pottery by SEMEDS and by micro-XRF-SEM. Micros Microanal. 2014;20:2030-1.

10. Goodhew PJ, Humphreys J, Beanland R. Electron microscopy and analysis, London: Taylor and Francis; 2001.

\section{Submit your manuscript to a SpringerOpen ${ }^{\circ}$ journal and benefit from:}

- Convenient online submission

- Rigorous peer review

- Immediate publication on acceptance

- Open access: articles freely available online

- High visibility within the field

- Retaining the copyright to your article 